\title{
Effects of X-ray irradiation in combination with ascorbic acid on tumor control
}

\author{
YOICHIRO HOSOKAWA ${ }^{1}$, SATORU MONZEN ${ }^{1}$, HIRONORI YOSHINO ${ }^{1}$, SHINGO TERASHIMA ${ }^{1}$, \\ MANABU NAKANO ${ }^{2}$, KEISUKE TOSHIMA ${ }^{3}$, RYO SAGA ${ }^{1}$ and IKUO KASHIWAKURA ${ }^{1}$ \\ Departments of ${ }^{1}$ Radiation Science and ${ }^{2}$ Bioscience and Laboratory Medicine, \\ Hirosaki University Graduate School of Health Sciences, Hirosaki, Aomori 036-8564; \\ ${ }^{3}$ Department of Radiology, Akita University Hospital, Akita, Akita 010-8543, Japan
}

Received June 3, 2014; Accepted June 17, 2015

DOI: $10.3892 / \mathrm{mmr} .2015 .4108$

\begin{abstract}
Our previous studies demonstrated that the combination of treatment with ascorbic acid (AsA) and X-ray irradiation results in increased apoptosis in HL60 cells. The present study was performed to investigate the effects of the combined use of AsA and X-ray irradiation on epithelial cancer and sarcoma cells, and its potential use in future clinical treatment. X-ray irradiation combined with AsA treatment resulted in increased suppression of cell growth of HT1080, SAS and A549 cells in vitro compared with $\mathrm{X}$-ray irradiation alone. The combined treatment also suppressed tumor growth in implanted HT-1080 cells in vivo. Using annexin $\mathrm{V} /$ propidium iodide staining and the detection of activated caspase 3 , it was found that X-ray irradiation increased the apoptotic rate of HT1080 cells and resulted in G2/M arrest. However, apoptosis in the HT1080 cells treated with $5 \mathrm{mM}$ AsA remained unchanged, and no changes were observed in the G2/M fraction. By contrast, AsA treatment caused increased suppression of proliferation compared with X-ray irradiation. These results suggested that $5 \mathrm{mM}$ AsA slowed the cell cycle and reduced tumor growth. Therefore, X-ray irradiation combined with AsA treatment may be effective against epithelial cancer and sarcoma cells.
\end{abstract}

\section{Introduction}

Cameron and Pauling first observed that ascorbic acid (AsA) exhibits antitumor properties and applied this finding to a clinical setting, however, their investigations date back $\sim 30$ years (1). At that time, the effectiveness of AsA for different purposes in addition to the treatment of cancer. However, the anticancer activity of AsA was not confirmed by clinical

Correspondence to: Professor Yoichiro Hosokawa, Department of Radiation Science, Hirosaki University Graduate School of Health Sciences, 66-1 Honcho, Hirosaki, Aomori 036-8564, Japan E-mail: hosokawa@hirosaki-u.ac.jp

Key words: X-ray irradiation, ascorbic acid, tumor control, cancer therapy investigations at the Mayo Clinic (Rochester, MN, USA), and AsA had not been considered for primary clinical therapies until recently (2). Previous studies have demonstrated that it is possible to administer a high intravenous dose of AsA, and that this can be applied for the treatment of cancer (3). The direct intravenous use of AsA in cancer treatment was demonstrated by Padayatty et al, who reported that three malignant tumor cases were controlled primarily by treatment with AsA (4). Furthermore, Padayatty et al reported side effects in only 101 of the 9,328 patients treated intravenously with AsA, and these were mostly minor effects (5).

Therefore, the present study investigated whether AsA in combination with X-ray irradiation exhibited an increased antitumor effect against HL60 cells, with the aim to use AsA in combination with radiation therapy in the future (6). Regarding the mechanism of apoptosis, it has been suggested that the involvement of $\mathrm{B}$-cell-associated $\mathrm{X}$ protein and caspase 8 differ following X-ray irradiation or treatment with AsA alone compared with the combined treatment with X-ray irradiation and AsA (7). The present study was performed to investigate the effect of the combined use of AsA and X-ray irradiation on epithelial cancer cells and its potential use in future clinical treatment.

\section{Materials and methods}

Cell culture. Human HT1080 fibrosarcoma cells were purchased from American Tissue Culture Collection (Rockville, IL, USA) and human A549 lung cancer cells and human SAS oral squamous cell carcinoma cells were purchased from the RIKEN Bio-Resource Center (Tsukuba, Japan). The HT1080 and SAS cells were maintained in RPMI-1640 (Gibco Life Technologies, Carlsbad, CA, USA), supplemented with $10 \%$ heat-inactivated fetal bovine serum (FBS; Japan Bioserum Co. Ltd., Fukuyama, Japan) in a $5 \% \mathrm{CO}_{2}$ incubator at $37^{\circ} \mathrm{C}$. The $\mathrm{A} 549$ cells were maintained in Dulbecco's modified Eagle's medium (DMEM; Sigma-Aldrich, St. Louis, MO, USA), supplemented with $10 \%$ heat-inactivated $\mathrm{FBS}$ in $5 \% \mathrm{CO}_{2}$ at $37^{\circ} \mathrm{C}$. All three cell lines were passaged at $75-90 \%$ confluence.

$X$-ray irradiation and AsA treatment in vitro. Culture dishes or microtiter plates containing the cells were exposed to X-rays 
from an X-ray machine (MBR-1520R-3; Hitachi, Tokyo, Japan) at $150 \mathrm{kV}$ and $20 \mathrm{~mA}$ through a $0.5-\mathrm{mm}$ aluminum and $0.3-\mathrm{mm}$ copper filter, at a dose rate of $1.0 \mathrm{~Gy} / \mathrm{min}$. Prior to X-ray irradiation and/or treatment with AsA (Wako Pure

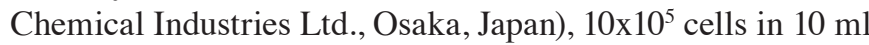
of medium were prepared in $10 \mathrm{~cm}$ dishes for $24 \mathrm{~h}$. The dishes were divided into four groups: Control, AsA alone, X-ray irradiation alone and X-ray irradiation combined with AsA. The AsA was dissolved to a final concentration of $5 \mathrm{mM}$ in medium following titration of the solution with $\mathrm{NaOH}$ (Wako Pure Chemical Industries Ltd.) to $\mathrm{pH}$ 7.4. The dishes treated with X-ray irradiation alone and X-ray irradiation combined with AsA, were irradiated $1 \mathrm{~h}$ after treatment with AsA.

Cell survival. HT1080 cells do not form colonies, and the cell survival rates of these cells as well as A549 and SAS cells were estimated without using colony assay in the present study. To remove all cells from the dishes following incubation, the cell monolayer was washed with phosphate buffered saline (PBS) and $0.1 \%$ trypsin/EDTA ( $1 \mathrm{ml}$ per $25 \mathrm{~cm}^{2}$ of surface area; Gibco Life Technologies, Carlsbad, CA, USA) was added to each well and incubated at $37^{\circ} \mathrm{C}$ for $2-10 \mathrm{~min}$. When all the cells had detached, the number of viable cells were quantified using a trypan blue exclusion test (Wako Pure Chemical Industries Ltd.). The cells were stained with $0.2 \%$ trypan blue for $1 \mathrm{~min}$ and counted to estimate the number of viable cells in $1 \mathrm{ml}$ medium.

Animal experiments. The animals used in the present study were maintained, and the experiments were performed, according to the Principles of Laboratory Animal Care established by the NIH. All animal experiments described were previously approved by the ethics committee of Hirosaki University (Hirosaki, Japan) and were performed in accordance with the Guidelines for the Care and Use of Laboratory Animals in Hirosaki University. Female, 5-week-old BALB/ cAJcl-nu/nu mice (CLEA Japan, Tokyo, Japan) were used in the present study. The mice were injected in the lateral neck with $200 \mu \mathrm{l}$ PBS, containing HT1080 cells $\left(5 \times 10^{6}\right.$ cells $\left./ \mathrm{ml}\right)$ 1 week after arrival at Hirosaki University. The mice were divided into four groups: Control, AsA alone, X-ray irradiation alone and X-ray irradiation combined with AsA. The treatment consisted of X-ray irradiation and/or AsA injection 7 days and 9 days after implantation of the HT1080 cells (Fig. 2A). AsA was dissolved in PBS at a concentration of $5 \mathrm{mM}$ and titrated with $\mathrm{NaOH}$ at $\mathrm{pH}$ 7.4. Each mouse in the AsA alone group and in the X-ray irradiation combined with AsA group were injected with $200 \mu \mathrm{l}$ AsA solution. In the X-ray irradiation group and X-ray irradiation combined with AsA group, a field (40x40 mm) was made using a lead plate, which was placed centrally over the tumor. The mice were anesthetized by intraperitoneal injection of sodium pentobarbital $(50 \mathrm{mg} / \mathrm{kg}$; Nembutor, Abbott Laboratories, Abbott Park, Il, USA) and were fixed in the prone position using synthetic rubber bands tied to each leg of the mouse. The mice were irradiated twice with 4 Gy with a total dose of $8 \mathrm{~Gy}$. The irradiation was the same as that used for the cells treated in vitro, as described above. The mice in the X-ray irradiation and AsA combination groups were irradiated 15 min following injection with the AsA. The long diameter and short diameter of the tumors on the skin were measured daily. All mice were sacrificed by cervical dislocation following $5 \%$ halothane (Wako Pure Chemical Industries Ltd.) inhalation, 13 days after implantation of the HT1080 cells. The tumor mass was subsequently removed from the lateral neck of the mice and was weighed.

Detection of apoptosis. The extent of apoptosis was determined by annexin V-Fluorescein isothiocyanate (FITC; BioLegend, San Diego, CA, USA) and propidium iodide (PI; Sigma-Aldrich) staining, according to the manufacturer's instructions. Following X-ray irradiation and/or treatment with AsA, the cells were cultured for $48 \mathrm{~h}$ at $37^{\circ} \mathrm{C}$. The cells were washed with PBS and suspended in $100 \mu \mathrm{l}$ annexin $\mathrm{V}$ binding buffer (BioLegend). The annexin V-FITC $(2.5 \mu \mathrm{g} / \mathrm{ml})$ and PI solution $(50 \mu \mathrm{g} / \mathrm{ml})$ were added to the cell suspension and incubated for $15 \mathrm{~min}$ at room temperature in the dark. The number of apoptotic cells were determined using flow cytometry (Cytomics FC500; Beckman-Coulter, Fullerton, CA, USA). In the annexin V/PI quadrant gating, annexin V(-)/ $\mathrm{PI}(-)$, annexin $\mathrm{V}(+) / \mathrm{PI}(-)$ and annexin $\mathrm{V}(+) / \mathrm{PI}(+)$ were used to identify the fraction of viable cells, early apoptotic cells and late apoptotic/necrotic cells, respectively (8).

Detection of activated caspase 3. An FITC-conjugated monoclonal active caspase 3 antibody kit for apoptosis (BD Biosciences, San Diego, CA, USA) was used to detect active caspase 3 , according to the manufacturer's instructions. The cells were cultured for $48 \mathrm{~h}$ following X-ray irradiation and/or treatment with AsA. The cells were washed with PBS, suspended in $500 \mu \mathrm{l}$ Cytofix/Cytoperm ${ }^{\mathrm{TM}}$ (BD Biosciences) and incubated for $20 \mathrm{~min}$ on ice. Following incubation, the cells were washed with Perm/Wash ${ }^{\mathrm{TM}}$ buffer (BD Biosciences) and resuspended in Perm/Wash ${ }^{\mathrm{TM}}$ buffer, containing 5\% FITC-conjugated rabbit anti-active caspase 3 antibody (cat. no. 559341; BD Pharmingen, San Diego, CA, USA). Following $30 \mathrm{~min}$ incubation at room temperature in the dark, the cells were washed and then analyzed by flow cytometry (Cytomics FC500; Beckman-Coulter).

Cell cycle analysis by flow cytometry. The HT1080 cells were seeded in $10 \mathrm{ml}$ RPMI-1640 ( $1 \times 10^{4}$ cells $\left./ \mathrm{ml}\right)$ in $100 \mathrm{~mm}$ culture dishes (Iwaki, Tokyo, Japan) and incubated at $37^{\circ} \mathrm{C}$ for $24 \mathrm{~h}$, in order to adhere to the dish. Following $\mathrm{X}$-ray irradiation and/or treatment with AsA, the cells were cultured for a specific duration. The cells were fixed with $70 \%$ ethanol (Wako Pure Chemical Industries Ltd.) overnight at $4^{\circ} \mathrm{C}$, washed with PBS and subsequently treated with RNase (200 $\mu \mathrm{g} / \mathrm{ml}$; Sigma-Aldrich) at $37^{\circ} \mathrm{C}$ for $30 \mathrm{~min}$ to hydrolyze the RNA. Following treatment, the cells were washed with PBS and stained with PI $(25 \mu \mathrm{g} / \mathrm{ml})$ for $30 \mathrm{~min}$ in the dark. A flow cytometer was used to analyze the cell cycle distribution.

Cell proliferation assay. Cell proliferation was measured using a cell proliferation ELISA, bromodexyuridine (BrdU) colorimetric kit (Roche, Basel, Switzerland). The cells $(20,000 / \mathrm{ml})$ in $200 \mu \mathrm{l}$ of medium were placed into each well of a 96 well microtiter plate $24 \mathrm{~h}$ prior to treatment. Following X-ray irradiation and/or treatment with AsA, the cells were added to $20 \mu \mathrm{l} \mathrm{BrdU}$ (Roche) and cultured for a specific duration. The cells were incubated with $20 \mu \mathrm{l} /$ well FixDenat solution (Roche) 
for $30 \mathrm{~min}$ and Anti-BrdU peroxidase (Roche) for $90 \mathrm{~min}$ at room temperature. The substrate reaction was measured using a spectrophotometer (Benchmark; Bio-Rad, Foster City, CA, USA) at $370 \mathrm{~nm}$.

Statistical analysis. All the data are expressed as the mean \pm standard deviation of at least three independent experiments. Statistical comparisons between the groups were performed using analysis of variance and Student's t-test. All statistical analyses were conducted using SPSS version 16.0 for Windows (SPSS Inc., Chicago, IL, USA). P $<0.05$ was considered to indicate a statistically significant difference.

\section{Results}

Growth suppression of HT1080, SAS and A549 cells by X-ray irradiation and/or AsA in vitro. The number of viable cells were quantified $72 \mathrm{~h}$ after $4 \mathrm{~Gy} \mathrm{X}$-ray irradiation and/or treatment with $5 \mathrm{mM}$ AsA. The percentage of viable cells compared with the control are shown in Fig. 1. The percentage of viable cells following treatment with AsA alone and X-ray irradiation alone significantly decreased in all three cell lines $(\mathrm{P}<0.05)$. In all three cell lines, the percentage of viable cells following $\mathrm{X}$-ray irradiation combined with AsA treatment were significantly lower compared with $\mathrm{X}$-ray irradiation alone $(\mathrm{P}<0.05)$.

Tumor growth suppression of transplanted HT-1080 cells by $X$-ray irradiation and/or AsA treatment in vivo. The initial weight of the mice increased relative to natural growth, however, on the eighth day following transplantation of the HT-1080 cells, the weight of the mice decreased (Fig. 2A). No significant difference in weight was observed between the four groups. The results of the tumor sizes (long diameter $\mathrm{x}$ short diameter) are presented in Fig. 2B and demonstrate that, in the control mice, the tumor size increased daily. No significant difference in tumor size was observed between the control group and those subjected to treatment with As A alone, although the tumor size did not increase following the second AsA treatment. The tumor size in the groups treated with X-ray irradiation alone and X-ray irradiation combined with AsA decreased following the second treatment. Furthermore, the tumor size in the X-ray irradiation combined with AsA group was lower compared with that in the X-ray irradiation alone group, with a significant difference between the two groups on the 13th day following transplantation of the HT-1080 cells $(\mathrm{P}<0.05)$. The weights of the tumor mass for each group on the $13^{\text {th }}$ day following the transplantation of HT-1080 cells is shown in Fig. 2C. The average tumor weight in the AsA alone group appeared lower compared with the control group, however, no significant difference was determined between the two groups. Statistical analysis revealed significant differences between the control group and the X-ray irradiation alone group, and between control group and $\mathrm{X}$-ray irradiation combined AsA treatment group $(\mathrm{P}<0.05)$. The average weight of the tumor in the X-ray irradiation combined with AsA group was significantly lower than that in the X-ray irradiation alone group $(\mathrm{P}<0.05)$.

Detection of apoptosis following X-ray irradiation and/or treatment with AsA. Annexin V/PI staining methods were used

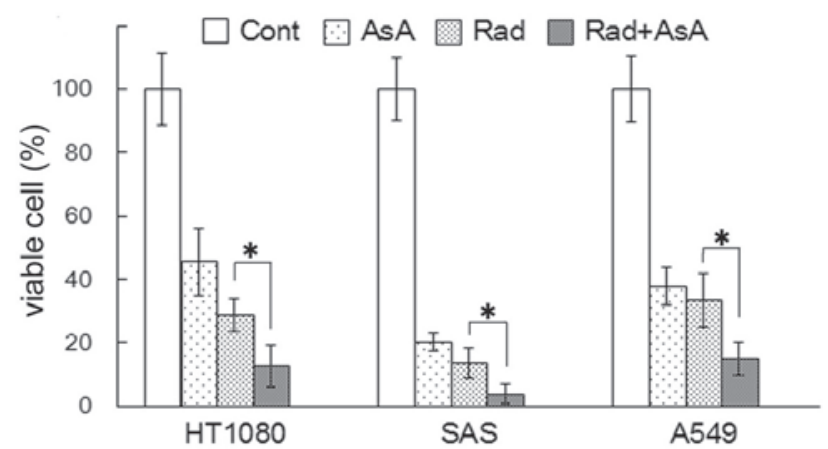

Figure 1. Relative number of viable cells following $78 \mathrm{~h}$ treatment with AsA alone (5 mM), Rad alone (4 Gy) or the two in combination. The viable cells were identified using a trypan blue exclusion assay $\left({ }^{*} \mathrm{P}<0.05\right)$. Data are expressed as the mean \pm standard deviation. Cont, control; AsA, ascorbic acid; Rad, X-ray irradiation.

A

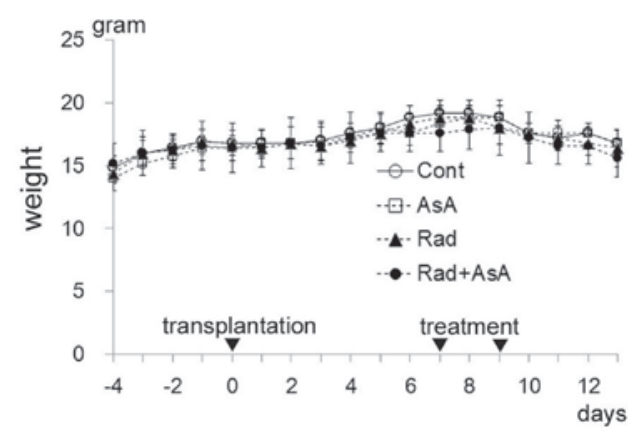

B

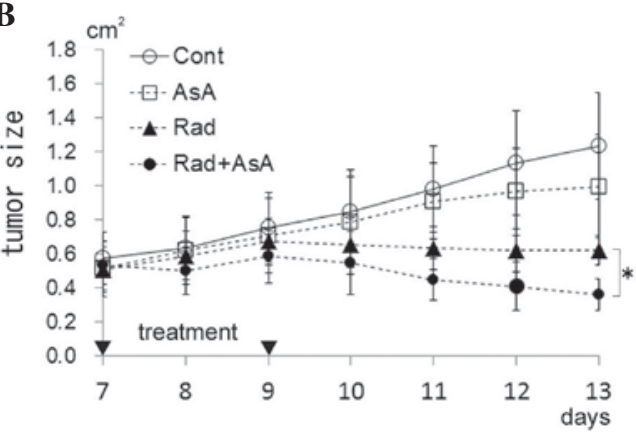

C

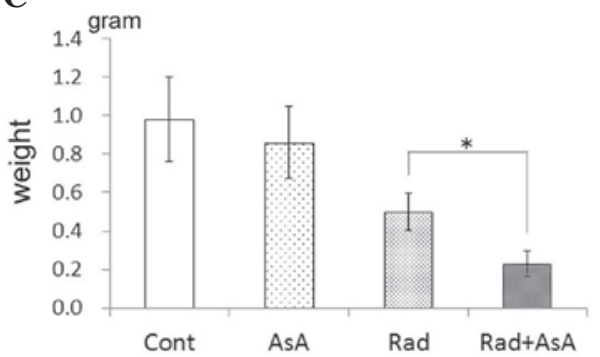

Figure 2. Effect of different treatments on mice transplanted with TH1080 cells. (A) Changes in body weights (B) tumor sizes (long diameter $\mathrm{x}$ short diameter) and (C) tumor weights 13 days after cell implantation in mice treated twice with AsA alone $(5 \mathrm{mM})$, Rad alone (4Gy) or the two combined. $\left({ }^{*} \mathrm{P}<0.05\right)$. Data are expressed as the mean \pm standard deviation. Cont, control; AsA, ascorbic acid; Rad, X-ray irradiation.

to analyze the induction of apoptosis. The percentage of early apoptotic annexin $\mathrm{V}(+) / \mathrm{PI}(-)$ cells and annexin $\mathrm{V}(+) / \mathrm{PI}(+)$ late apoptotic cells were significantly higher in the groups treated 
A

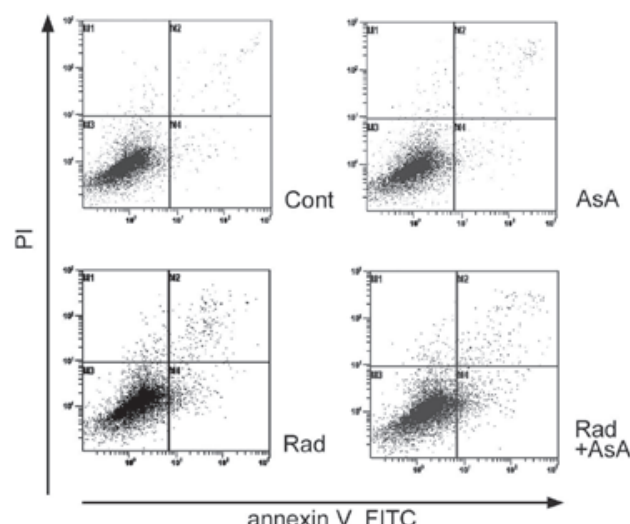

C

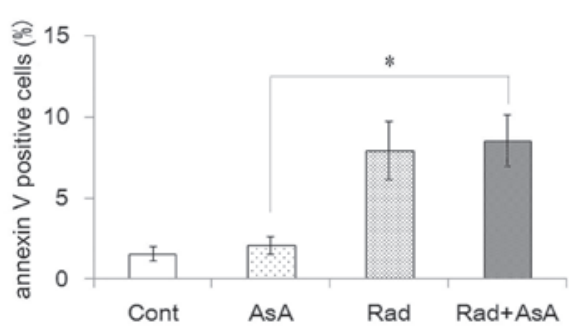

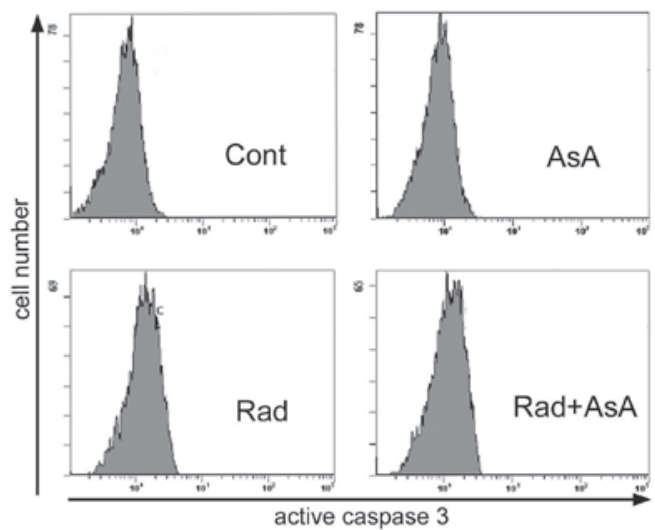

D

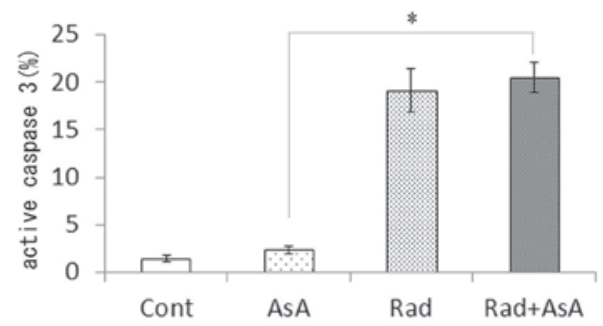

Figure 3. Induction of apoptosis in the HT1080 cells. The HT1080 cells were incubated for $48 \mathrm{~h}$ following cell implantation in mice treated twice with AsA alone (5 mM), Rad alone (4Gy) or the two combined. Representative images of (A) annexin/PI staining and (B) expression of active caspase 3, which were analyzed by flow cytometry. (C) Percentages of annexin(+)/PI(-) and annexin(+)/PI(+) cells were analyzed using flow cytometry. (D) Percentage of active caspase 3 cells, determined using flow cytometry. ( $\left.{ }^{*} \mathrm{P}<0.05\right)$. Data are expressed as the mean \pm standard deviation. Cont, control; AsA, ascorbic acid; Rad, X-ray irradiation; PI, propidium iodide; FITC, fluorescein isothiocyanate.

with X-ray irradiation and X-ray irradiation in combination with AsA, compared with the control and the group treated with AsA alone $(\mathrm{P}<0.05$; Fig. 3A and $\mathrm{C})$. However, no statistically significant difference was observed between the control cells and those treated with AsA alone. In addition, no statistically significant difference was observed between the cells treated with X-ray irradiation alone and X-ray irradiation combined with AsA. To further investigate the induction of apoptosis, the expression levels of activated caspase 3 , an executioner of apoptosis, were analyzed. The activation of caspase 3 was higher in cells treated with X-ray irradiation and X-ray irradiation combined with AsA compared with the control and the group treated with AsA alone (Fig. 3B and D). However, no statistically significant difference was observed in the activation of caspase 3 between the control cells and those treated with AsA. In addition, no statistically significant difference was observed between the cells from the $\mathrm{X}$-ray irradiation and X-ray combined AsA groups.

Changes in cell cycle profile and cell proliferation following $X$-ray irradiation and/or treatment with AsA. The effect of $\mathrm{X}$-ray irradiation and/or treatment with AsA on the cell cycle profile of HT1080 cells was analyzed (Fig. 4). X-ray irradiation and X-ray irradiation combined with AsA increased the number of cells in the G2/M fraction following $12 \mathrm{~h}$ treatment, compared with the control and AsA alone groups $(\mathrm{P}<0.05$; Fig. 4A). Treatment with X-ray irradiation alone and combined with AsA significantly increased the sub-G1 fraction following treatment for $72 \mathrm{~h}$ compared with the control and treatment with AsA alone ( $\mathrm{P}<0.05$; Fig. 4B). By contrast, no statistically significant differences were observed in the cell cycle profiles between the control cells and those treated with AsA alone, nor between the cells treated with X-ray irradiation alone and in combination with AsA. However, the proliferation of cells following treatment with AsA, with or without X-ray irradiation were lower compared with the control, and a significant difference was observed between the groups treated with $\mathrm{X}$-ray irradiation alone and $\mathrm{X}$-ray in combination with AsA treatment $(\mathrm{P}<0.05$; Fig. 5).

\section{Discussion}

AsA exhibits cytotoxic effects on tumor cells, which have a low concentration of intracellular catalase to degrade hydrogen peroxide $\left(\mathrm{H}_{2} \mathrm{O}_{2}\right)$ (9). Previous studies have demonstrated that tumor cells are easily damaged by $\mathrm{H}_{2} \mathrm{O}_{2}$, and the production of adenosine triphosphate is decreased as a result of mitochondrial damage, leading to tumor cell death $(10,11)$. When AsA is added to culture in the presence of catalase, the cytotoxic effects of AsA disappear (6). The majority of the cell death induced by X-ray irradiation depends on the production of intracellular reactive oxygen species (ROS), which are produced during irradiation. Within several hours of irradiation, secondary ROS production occurs intracellularly, which induces apoptosis (12). When cell cultures are exposed to X-ray irradiation in the presence of catalase, the cytotoxic effects of the X-rays do not disappear (13). This suggests that the production of ROS following X-ray irradiation differs from that produced following treatment with AsA (6). 
A

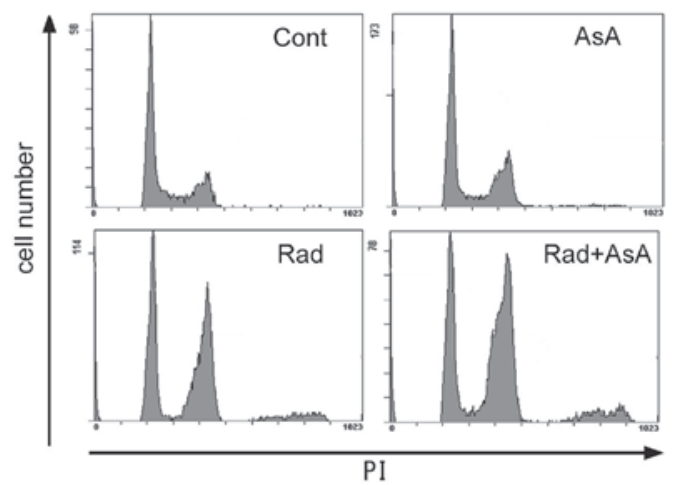

C

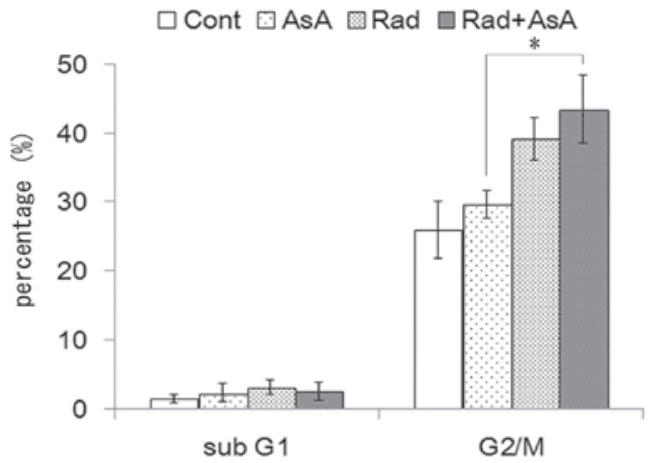

B

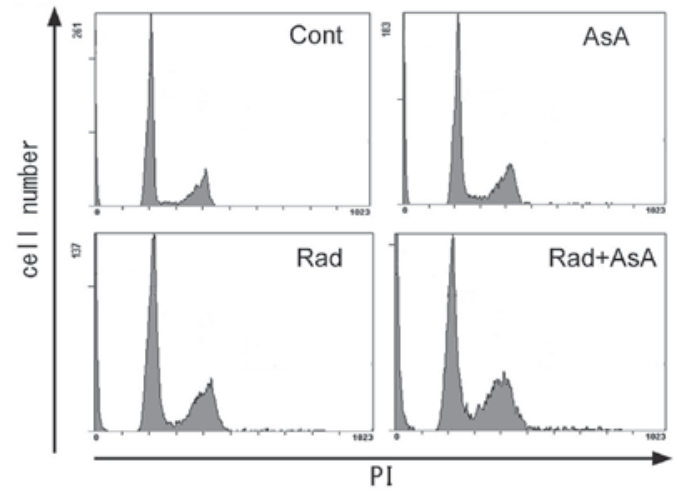

D

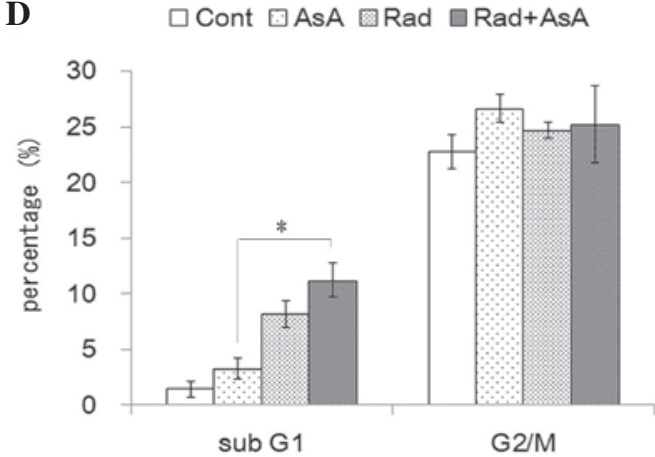

Figure 4. Cell cycle analysis in the HT1080 cells using flow cytometry. Representative histograms of the cell cycle profiles of HT1080 cells incubated for (A) $12 \mathrm{~h}$ or (B) $72 \mathrm{~h}$ following cell implantation in mice treated twice with AsA alone (5 mM), Rad alone (4Gy) or the two combined. The percentages of sub-G1 and G2/M phase cells (C) $12 \mathrm{~h}$ and (D) $72 \mathrm{~h}$ following cell implantation in mice treated twice with AsA alone (5 mM), Rad alone (4Gy) or the two combined. $\left({ }^{\prime} \mathrm{P}<0.05\right)$. Data are expressed as the mean \pm standard deviation. Cont, control; AsA, ascorbic acid; Rad, X-ray irradiation; PI, propidium iodide.

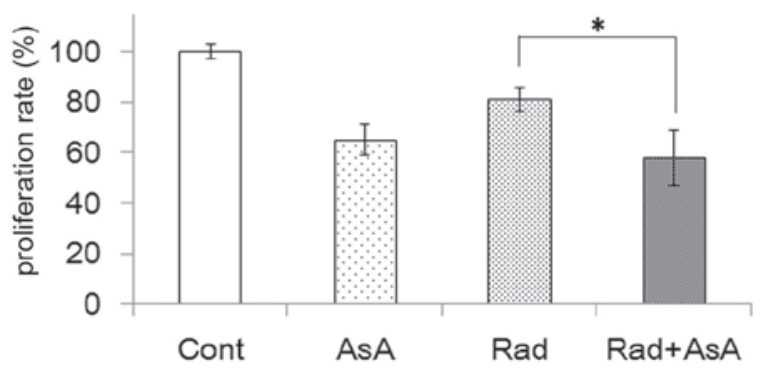

Figure 5. Proliferation rate analyzed by ELISA $24 \mathrm{~h}$ following cell implantation in mice treated twice with AsA alone ( $5 \mathrm{mM}$ ), Rad alone (4Gy) or the two combined. $\left({ }^{*} \mathrm{P}<0.05\right)$. Data are expressed as the mean \pm standard deviation. Cont, control; AsA, ascorbic acid; Rad, X-ray irradiation.

Padayatty et al demonstrated that an AsA concentration $\geq 1 \mathrm{mM}$ in the blood, administered by intravenous injection, is required for the effective treatment of cancer, and that a concentration of $\sim 5 \mathrm{mM}$ is optimal (4). In clinical investigations performed by Hoffer et al, it was observed that when AsA is administered at a blood concentration of $5 \mathrm{mM}$, no side effects are observed in humans (14). In the present study, the effects of a combined treatment of $5 \mathrm{mM}$ AsA and X-ray irradiation on epithelial cancer cells and sarcoma cells were examined. Several previous studies have also used $5 \mathrm{mM}$ AsA in their investigations to determine its direct effect in vitro and by diffusion into the human body (15-17).
In the present study, X-ray irradiation combined with AsA suppressed the growth of the epithelial cancer and sarcoma cells in vitro (Fig. 1) and suppressed the growth of implanted HT-1080 tumor cells in vivo (Fig. 2). The suppression on cell growth observed following X-ray irradiation combined with AsA was significantly higher compared with that observed following X-ray irradiation alone. These data indicated that combining X-ray irradiation with AsA treatment is beneficial for cancer therapy. Few studies have investigated the use of AsA with radiotherapy in tumor control. This may be due to the fact that AsA is a well-known free radical scavenger and that the anticancer effects of X-ray irradiation, which attack tumor cells by generating $\mathrm{OH}$ radicals may disappear $(18,19)$. However, treatment with AsA has failed to inhibit the anticancer effects of X-ray irradiation when used in combination with X-ray irradiation $(6,7)$.

The results of the present study demonstrated that X-ray irradiation increased the apoptotic rate of HT1080 cells. An increase in the $\mathrm{G} 2 / \mathrm{M}$ fraction at $12 \mathrm{~h}$ and sub-G1 fraction at $72 \mathrm{~h}$ was observed in the HT1080 cells exposed to X-ray irradiation. It is likely that X-ray irradiation induced DNA damage and resulted in $\mathrm{G} 2 / \mathrm{M}$ arrest in preparation for programmed cell death (20). However, the apoptotic rate was not increased in the HT1080 cells treated with $5 \mathrm{mM}$ AsA, and no changes were observed in the $\mathrm{G} 2 / \mathrm{M}$ fraction at $12 \mathrm{~h}$ or sub-G1 fraction at $72 \mathrm{~h}$. By contrast, treatment with AsA caused higher levels of suppression on cell proliferation compared with X-ray 
irradiation alone. Considering these results, $5 \mathrm{mM}$ AsA may slow the cell cycle without changing the cell cycle fraction rate, leading to reduced tumor growth.

Several studies have investigated apoptosis as part of tumor inhibition by AsA $(21,22)$. The present study confirmed that apoptosis in the HT1080 cells was induced and G2/M cell cycle arrest was observed following treatment with $>10 \mathrm{mM}$ AsA (data not shown). It is well-known that cell cycle arrest can be readily induced in blood cells (23). The present study demonstrated that, even with $5 \mathrm{mM}$ AsA, cell growth was suppressed in the epithelial cancer and sarcoma cells, which were relatively radioresistant without apoptosis. The marked inhibition of cell growth observed in the cells treated with X-ray irradiation combined with AsA treatment appeared to be attributed to the combined effect of X-ray irradiation and the added suppressive effect of AsA on cancer cells. Therefore, $\mathrm{X}$-ray irradiation combined with AsA treatment may be effective against solid tumors (24).

In conclusion, X-ray irradiation combined with AsA treatment suppressed the growth of HT1080, SAS and A549 cells in vitro, and reduced tumor mass following implantation of HT-1080 in vivo. Treatment with $5 \mathrm{mM}$ AsA caused a higher suppression of cell proliferation compared with X-ray irradiation alone, although apoptosis was not increased. This may explain why X-ray irradiation combined with AsA led to more marked inhibition of cancer cell growth compared with X-ray irradiation alone. Since AsA administration was observed to be non-toxic in humans, AsA may be important in potential future radiotherapy (23).

\section{Acknowledgements}

The present study was supported by the Japan Society for the Promotion of Science (Grants-in-Aid for Scientific Research, project nos. 21591603 and 24591831).

\section{References}

1. Cameron E and Pauling L: Ascorbic acid and cancer: a review. Proc Natl Acad Sci USA 75: 4538-3542, 1987.

2. Creagan ET, Moertel CG, O'Fallon JR, Schutt AJ, O'Connell MJ, Rubin J and Frytak S: Failure of high-dose vitamin C (ascorbic acid) therapy to benefit patients with advanced cancer. A controlled trial. N Engl J Med 301: 687-690, 1979.

3. Duconge J, Miranda-Massari JR, Gonzalez MJ, Jackson JA, Warnock W and Riordan NH: Pharmacokinetics of vitamin C: insights into the oral and intravenous administration of ascorbate. P R Health Sci J 27: 7-19, 2008.

4. Padayatty SJ, Riordan HD, Hewitt SM, Katz A, Hoffer LJ and Levine M: Intravenously administered vitamin $\mathrm{C}$ as cancer therapy: three cases. CMAJ 174: 937-942, 2006.

5. Padayatty SJ, Sun AY, Chen Q, Espey MG, Drisko J and Levine M: Vitamin C: intravenous use by complementary and alternative medicine practitioners and adverse effects. PLoS One 5: e11414, 2010
6. Terashima S, Hosokawa Y, Yoshino H, Yamaguchi M and Nakamura T: Effect of ascorbic acid and X-irradiation on HL-60 human leukemia cells: the kinetics of reactive oxygen species. Oncol Rep 30: 2653-2658, 2013.

7. Shinozaki K, Hosokawa Y, Hazawa M, Kashiwakura I, Okumura K, Kaku T and Nakayama E: Ascorbic acid enhances radiation-induced apoptosis in an HL60 human leukemia cell line. J Radiat Res (Tokyo) 52: 229-237, 2011.

8. Wakasaya T, Yoshino H, Fukushi Y, Yoshizawa A and Kashiwakura I: A liquid crystal-related compound induces cell cycle arrest at the G2/M phase and apoptosis in the A549 human non-small cell lung cancer cell line. Int J Oncol 42: 1205-121, 2013.

9. Chen Q, Espey MG, Sun AY, et al: Ascorbate in pharmacologic concentrations selectively generates ascorbate radical and hydrogen peroxide in extracellular fluid in vivo. Proc Natl Acad Sci USA 104: 8749-8754, 2007.

10. Takemura Y, Satoh M, Satoh K, Hamada H, Sekido Y and Kubota S: High dose of ascorbic acid induces cell death in mesothelioma cells. Biochem Biophys Res Commun 394: 249-253. 2010.

11. Bordignon B, Mones S, Rahman F, Chiron J, Peiretti F, Vidal N and Fontes M: A derivative of ascorbic acid modulates cAMP production. Biochem Biophys Res Commun 439: 137-141, 2013.

12. Kam WW and Banati RB: Effects of ionizing radiation on mitochondria. Free Radic Biol Med 65: 607-619, 2013.

13. Klingelhoeffer C, Kämmerer U, Koospal M, et al: Natural resistance to ascorbic acid induced oxidative stress is mainly mediated by catalase activity in human cancer cells and catalase-silencing sensitizes to oxidative stress. BMC Complement Altern Med 12: 61, 2012.

14. Hoffer LJ, Levine M, Assouline S, et al: Phase I clinical trial of iv ascorbic acid in advanced malignancy. Ann Oncol 19: 1969-1974, 2008

15. Putchala MC, Ramani P, Sherlin HJ, Premkumar $P$ and Natesan A: Ascorbic acid and its pro-oxidant activity as a therapy for tumours of oral cavity - a systematic review. Arch Oral Biol 58: 563-574, 2013.

16. Du J, Cullen JJ and Buettner GR: Ascorbic acid: chemistry, biology and the treatment of cancer. Biochim Biophys Acta 1826: 443-457, 2012

17. Ha YM, Park MK, Kim HJ, Seo HG, Lee JH and Chang KC: High concentrations of ascorbic acid induces apoptosis of human gastric cancer cell by p38-MAP kinase-dependent up-regulation of transferrin receptor. Cancer Lett 277: 48-54, 2009.

18. Fukumura H, Sato M, Kezuka K, et al: Effect of ascorbic acid on reactive oxygen species production in chemotherapy and hyperthermia in prostate cancer cells. J Physiol Sci 62: 251-257, 2012.

19. Witenberg B, Kletter Y, Kalir HH, et al: Ascorbic acid inhibits apoptosis induced by X irradiation in HL60 myeloid leukemia cells. Radiat Res 152: 468-478, 1999.

20. Gupta A, Hunt CR, Chakraborty S, et al: Role of 53BP1 in the regulation of DNA double-strand break repair pathway choice. Radiat Res 181: 1-8, 2014

21. Vuyyuri SB, Rinkinen J, Worden E, Shim H, Lee S and Davis KR: Ascorbic acid and a cytostatic inhibitor of glycolysis synergistically induce apoptosis in non-small cell lung cancer cells. PLoS One 8: e67081, 2013.

22. Traber MG and Stevens JF: Vitamins C and E: beneficial effects from a mechanistic perspective. Free Radic Biol Med 51: 1000-1013, 2011.

23. Harakeh S, Diab-Assaf M, Khalife JC, et al: Ascorbic acid induces apoptosis in adult T-cell leukemia. Anticancer Res 27 (1A): 289-298, 2007

24. Stephenson CM,Levin RD, Spector T and Lis CG: Phase I clinical trial to evaluate the safety, tolerability and pharmacokinetics of high-dose intravenous ascorbic acid in patients with advanced cancer. Cancer Chemother Pharmacol 72: 139-146, 2013. 